\title{
Green Filter Development: An Innovative Technique for Removal of Heavy Metals from Water
}

\author{
Nikita Verma ${ }^{1}$, Rajeev Kumar ${ }^{2 *}$, Mahipal Singh Sankhla ${ }^{3}$, Kapil Parihar ${ }^{3}$ \\ ${ }^{1}$ Student of M.Sc. Forensic Science, SBAS, Galgotias University, Greater Noida, India \\ ${ }^{2}$ Associate Professor, Forensic Science, SBAS, Galgotias University, Greater Noida, India \\ ${ }^{3}$ Research Scholar, Forensic Science, SBAS, Galgotias University, Greater Noida, India
}

*Corresponding Author: Rajeev Kumar, Associate Professor, Forensic Science, SBAS, Galgotias University, Greater Noida, India, Email: rajeev4n6@gmail.com

\begin{abstract}
There are many impurities present in contaminated water that adversely affect our food chain, humans, animals, plants etc. Different water bodies get contaminated through toxic materials which are executed through industries, e-waste, dyes, chemical compounds etc. due to which their contamination level increases significantly. There's a need to remove these elements from contaminated water so as to protect ourselves and our food cycle. Earlier so many techniques were used for removing contaminants from contaminated water. But now a day, a latest technique "Green Filters" is used to remove contaminants from contaminated water. Green filters are considered as eco friendly and is also cost effective. This paper mainly focuses on depth review of green filter and its competence to remove contaminants from water.
\end{abstract}

Keywords: Green Filters, Water, GAC, Toxicity, etc.

\section{INTRODUCTION}

Water has an immense affect on human life including everything fitness, meal, efficiency, and economy. With rise to the environmental, economic, and social impacts of poor water supply and sanitation (D. D. Mara et.al; 2003, M. Moore, et. al; 2003), the health of population specially of vunerable class (children, the elderly and poor), are much affected by fling of sufficient, secure and economical water supplies (J. Theron and T. E. Cloete et.al; 2002). Due to waterborne and non fatal infection, about millions of human beings expired every year (P. Leonard et.al; 2003).

Major water related problems like that of diarrhea about thousands of children die every year. In present scenario, billions of people are lacking ingress to safe aqua resources (WHO and UNICEF, 2013) leads to major health problems. There's billions of population in the universe who do not have safe water ingress and it is assuming that within couple of decades the current water supply will decrease by one-third. Toda, one of the most complex environmental issues is Metal contamination. Heavy metals accumulation in water and soil need to be observed as it gives negative impact on human heath by entering food chain (Sadonet.al; 2012 .Prevention and reuse of contaminated water receives a prime attention globally due to increasing demand of agriculture, domestic purposes (Opeolu and Fatokiet.al; 2012). Nanotechnology is the branch of knowledge which gives information regarding manipulation, use of materials and production which ranges in nanometers. Nanomaterials research is considered as chief characteristics because of its multifarious applications. In the branch of, antimicrobials, bio-medical, catalyst, bio-labeling, sensors and in further zones nanomaterials shows a wide range of its application (Salam ha et.al 2012). Plant resources are used in the production of various nanomaterials. Plants contain different remedial components which are used as traditional medicine. Plants have huge diversity due to which it is used in the branch of agricultural, pharmaceuticals, industrial zones etc. With the current study of flora towards manufacturing of nanomaterials, it has been observed that plants plays a role of trump card because of its easily availability, can handle safely and have vast parameter of biomolecules such as terpenoids, flavonoids tannins, etc. which are known to arbitrate nanoparticles composite. Nanomaterials can be associated with other materials, such as silica, graphene, activated carbon, using them as pillar (Bragança 
LFFPG et.al; 2013; Wouters B et.al; 2014; Liu X, et.al; 2013; Li Let.al; 2014; Yamaguchi NU et.al; 2016) The activated carbon has welldeveloped internal pores, large surface area and high surface reactivity and thus called as an effective adsorbent (Kalijadis AM, et.al; 2011). Activated carbon plays an important role in the adsorption process due to its structural properties. Properties of activated carbon can be modified by saturated zinc salts, copper, iron, chromium metals over its surface, (Hosseini S et.al; 2015). Heavy metals such as cadmium, chromium, lead are non biodegradable and are toxic at low concentration can cause a significant problems to humans, animals, plants (P. Trivedi et.al; 2000). The lead released into the environment by industrial sources like finishing, ammunition, tetraethyl lead manufacturing, battery manufacturing, acid metal plating and glass printing industries. On the other side, through drinking water lead can enter the food chain and from waste water can enter crop irrigation and thus considered as a widespread problem. Lead has the property of nonbiodegradable, and it can bio-accumulate in living organisms cells (L.Yan-ui, et. al; 2006). Lead shows impact on living organism as to damage the liver, nervous system, brain, kidney, and reproductive systems. Removal of Arsenic from water is significant subject worldwide, which has recently attracted great attentions. Various methods has been introduced for elimination of Arsenic from water, including, adsorption (Wang et.al; 2002; Zhang et.al; 2003; Katsoyiannis and Zouboulis, et. al; 2002), coagulation (precipitation) (Wickrama singhe et. al; 2004; Heringet.al; 1997) ion exchange, membrane filtration, electro coagulation, biological process, iron oxide-coated sand, high gradient magnetic separation and natural iron ores etc. Drinking water which contains in orgain arsenic (concentration above $50 \mu \mathrm{g} / \mathrm{L}$ ), shows different kinds of cancers (skin, kidney, lungs, bladder) and skin lesions (hyperkeratosis, hyper pigmentation), are known as arsenicosis (Singh R, et. al; 2014). Arsenic is one of the fatal metals. From aqueous solution heavy metal ions can be removed by chemical precipitation, reverse osmosis electrochemical treatment, adsorption (Z. Elouear, et.al; 2008; J.T. Mayo, et.al; 2007; R. Leyva-Ramos et.al; 1997). Among the all above mentioned treatments, adsorption technology is considered to be best because of its economical availability, effectiveness, and trouble-free procedures without giving any detrimental by-products (G. Crini, et.al; 2005). Adsorption is transfer of mass from liquid point to solid surface, and it becomes bounded by chemical or physical interactions. The primarily adsorbents include zeolites, biomass, activated carbon, clays, etc. (G. Crini, et.al; 2006)

\section{PLANTS}

Plants have the possible unused quality to get together certain amount of heavy metals in their different parts. As an outcome of that, biosynthesis techniques which employs plant extracts have been increased as it is simple, cost effective and practicable methods as well as an tremendous substitute to conventional preparation methods for nanomaterials production.(Singh, J., Dutta,et.al;2018),Plants have bimolecular (coenzyme, carbohydrates, proteins) and have excellent prospective to reduce metal salts into nanomaterials.

"Green" synthesis contains two major routes:

- Solvent system is taken as water.

- A natural extract is considered as the chief constituent.

\subsection{Plant leaf extract-based mechanism}

At different reaction conditions, plant leaf extract is assorted with metal pioneer solutions for production of nanoparticles. (Mittal AK et.al; 2013) The parameters determining the conditions of the plant leaf are admitted to control .With the help of plant leaf extract, rate of nanoparticle formation, stability, yield can be determine (phytochemical, concentration, $\mathrm{pH}$, and metal salt temperature) (Dwivedi $\mathrm{AD}$,et.al;2010). Phytochemicals which are present in plant leaf extract have potential to reduce metals ions in shorter instance than fungi, bacteria (Jha AK et.al; 2009). Thus, leaf extracts of plant is known as an tremendous source for synthesis for both metal oxides and metals nanoparticles., For nanoparticles synthesis process leaf extract of plants play double function by acting as both reducing agent as well as stabilizing agent (Malik P, et.al; 2014) Different plants comprises of different concentration levels of phytochemicals therefore plant leaf extract plays an important role in synthesis of nanoparticles. ( $\mathrm{Li} \mathrm{X}$ et.al; 2013)( Mukunthan KSet.al;2012).The main phytochemicals present in plants which are responsible for bioreduction of nanoparticles are terpenoids, flavones, ketones, aldehydes, carboxylic acids, sugars, etc (Prathna TC,et.al;2010) . The nanoparticles synthesis was monitored with the help of UV-Vis 
absorption spectroscopy and was characterized by TEM, FTIR, and SEM.

\subsection{Granular Activated Carbon (GAC)}

Granular activated carbon (GAC) has been known as one of the most accepted and extensively used adsorbent in water and wastewater treatment (J.W. Hassler, et.al;1974 ; J.R.Perrich,et.al;1981;H.Marsh,et.al;2005;R.C. Bansal,et.al;2005;T.J.Bandosz,et.al;2006).One of the oldest adsorbent known in water purification is Charcoal(modern activated carbon ).Scheele in 1773 had discovered specific adsorptive properties of charcoal for the treatment of gases followed by decolorizing of solutions in 1786 and he also gives information of the first methodical explanation of the adsorptive control of charcoal in the liquid phase (H. Sontheimer,et.al;1988). Carbon based materials which contains well developed internal pore structure is described by the term activated carbon. It is formed by a variety of carbonaceous rich materials like wood, lignite coal, coconut shell (J.W. Hassler, et. al; 1980). On the exterior of AC, it has well developed internal pores consisting of meso, macropores, micro-, the high surface area and a wide variety of functional groups present which make it a adaptable material and has abundant applications in many zones mainly in the field of environment. It is found that activated carbon has much efficient property in removing organic compounds as compared to metals and other inorganic pollutants.

\subsection{Green Synthesis}

Green synthesis is known as an important tool for reducing the destructive effects associated with the traditional methods of synthesis for nanoparticles commonly utilized in laboratory and industry. The morphological criteria of nanoparticles (shape and size) can be regulated by varying the concentrations of chemicals and reaction conditions ( $\mathrm{pH}$, temperature). Synthesized nanomaterials can experience from the following challenges if they are subjected to actual applications:

- constancy in hostile environment,

- bioaccumulation features,

- requirement of skillful operators,

- difficulty in assembling of devices and structures,

- Recover/recycle/renewal.
It is important that properties, types of nanomaterials and its behaviour should be improved to meet the abovementioned points. On the other side, these limitations are opening innovative opportunities in research field. To tackle those limitations, a new era of green synthesis approaches is gaining great attention towards current research and development on materials science and technology. Several components like deterrence of waste, reduction of derivatives, and the utilize of non-toxic solvent as well as renewable feedstock can give explanation of some basic doctrine of green synthesis. Green synthesis is required to avoid the production of unnecessary by-products through the build-up of sustainable, consistent, and eco-friendly synthesis procedures. The exercise of ideal solvent systems and natural resources (organic systems) are essential to achieve this goal. To accommodate various biological materials Green synthesis of metallic nanoparticles has been adopted .Among the accessible green procedure of metal oxide/metal nanoparticles synthesis, utilization of plant extracts is simple and easy method to fabricate nanoparticles at large scale in contrast to bacteria, fungi mediated synthesis. These products are collectively called as biogenic nanoparticles. Green syntheses methodologies are based on organic precursors depend on a variety of reaction parameters like, temperature, $\mathrm{pH}$, solvent conditions, and pressure. For the synthesis of metal/metal oxide nanomaterials, due to the accessibility of efficient photochemicals in various plant extracts, especially in leaves like flavones ketones, terpenoids, ketones, carboxylic acids, aldehydes, phenols, plant biodiversity has been broadly considered. These components are competent of reducing metal salts into metal nanomaterials (Doble M et.al; 2007). The investigation of nanopaticles has been done to take its advantage in field of molecular sensing, biomedical diagnostics, catalysis, optical imaging, antimicrobials, and labelling of biological systems (Aguilar Z et.al; 2013).

\section{REMOVAL METHOD FOR CADMIUM IN WASTE WATER}

Ficus tree (Ficus Benjamina) leaves were taken. Leaves belongs to the Moraceae family and is one of the maximum rich flowering plant life in Australia and Asia. These leaves can also be developed in the environment of Florida and Arizona in the United States and in the West Indies. 
FicusBenjamina tree can spread upto $30 \mathrm{~m}$ in unusual situations. The leaves were dirt free with tap water, de-ionized water and desiccated in oven at $50 \mathrm{C}$ before cut into small particles. $20 \mathrm{~g}$ of leaves of FicusBenjamina was taken in Erlenmeyer flask $(250 \mathrm{~mL})$ to make extract, then distilled water was added in quantity of $100 \mathrm{ml}$, previous solution was further boiled for $5 \mathrm{~min}$ $(60 \mathrm{C})$. Mixture was boiled for 5 minute slateron, then mixture should be cleaned and at $4 \mathrm{C}$ the filtrate will be stored. $\mathrm{Ag} 0$ nanomaterials procedure, $2 \mathrm{ml}$ of FicusBenjamina leaf extract (FBLE) was taken and $25 \mathrm{~mL}$ of AgNO3 (1 Mm) was added. The pigment colour changes to brown. Finally, the solution was stimulated for $40 \mathrm{~min}$ to make silver nanoparticles. This testing was done at room temperature $(25 \mathrm{C})$. The brown color indicates the presence of $\mathrm{Ag}$ nanoparticles. Within 20 min colour changes to brown which indicates that AgNPs is formed. Characterizations of $\mathrm{Ag}$ nanoparticles were studied. Further illustrations were examined under $\mathrm{UV}-\mathrm{V}$ is spectrophotometer. $\mathrm{UV}-\mathrm{V}$ is measuring lead: Varian ICP - AES. FT-IR study were completed to observe the progress of nanomaterials of Ago. For dried nanomaterialsFT-IR ranges were taken, the samples dust were crushed with potassium bromide for FTIR spectra tests. Scanning electron microscopy (SEM): A tinny picture of nanomaterials was considered on a copper slide confined with carbon, then impaire paper was used to eradicate the removal resolution and dried the picture beneath the mercury spotlight for $5 \mathrm{~min}$. Prior to the picture it was positioned in the container and obtained hooked on the microscope (K.M. Al-Qahtaniet.al;2017).

\section{Removal Method of Lead From WATER}

Brown seaweeds that are Padina pavonica (Linnaeus), Sargassum acinarium (Linnaeus) was taken. They are broadly distributed alongside Egyptian Mediterranean Coast, particularly in Alexandria coast. The preferred species were collected from the rocky site near Boughaz El-Maadya and Abu-Qir Bay of Alexandria coast, Egypt.

All seaweeds were cleaned, freeze-dried at $20^{\circ} \mathrm{C}$ for $3 \mathrm{~d}$ and then ground to fine powder using a Waring miller to pass through a $0.5-\mathrm{mm}$ screen. Firstly, $100 \mathrm{~mL}$ distilled water $(100 \mathrm{~mL})$ was taken in an Erlenmeyer flask and ground freeze-dried seaweed samples (about $1 \mathrm{~g}$ ) were added to it and boiled further continuously stirred for $15 \mathrm{~min}$. For the biosynthesis of
Fe3O4 -NPs the gren filter extract was cooled down to room temperature, filtered. By using the co-precipitation method magnetite ( $\mathrm{Fe} 3 \mathrm{O} 4)$ NPs were prepared. Seaweed extract was added to $\mathrm{FeCl} 3(0.1 \mathrm{~mol} / \mathrm{L})$ solution in a $1: 1$ volume ratio. With the reduction procedureFe3O4 -NPs were obtained instantly. The seaweed mixture was enthused for $60 \mathrm{~min}$ and then permitted to set at room temperature for next $30 \mathrm{~min}$. Centrifuge the obtained colloidal suspension and use ethanol to washed it and to obtain the $\mathrm{Fe} 3 \mathrm{O} 4$ -NPs it should be desiccated at $40^{\circ} \mathrm{C}$ under vacuum. The color changes from yellow to brown. Colour changes to brown because of excitation of the exterior plasmon resonance in the metal nanoparticle.

.Infrared spectroscopy UV-Vis spectral study was executed to corroborate the biosynthesis of $\mathrm{Fe} 3 \mathrm{O} 4$-NPs and by UV-Vis spectrophotometer the absorption peak was scanned at wavelength of $350-800 \mathrm{~nm}$ on Perkin-Elmer Lambda 25 spectrophotometer.

Electron microscopy; on the carbon-coated copper grids, a drop $(50 \mu \mathrm{L})$ of Fe3O4 -NPs colloid was placed. Transmission Electron Microscope (TEM) is used to analyse the size and morphology of Fe3O4 nanoparticles. FTIR is used for measuring the biosynthesized $\mathrm{Fe} 3 \mathrm{O} 4$ -NPs colloid and it was centrifuged for $15 \mathrm{~min}$ at $10000 \mathrm{~g}$ and $\mathrm{KBr}$ pellets was added to grind the lyophilized samples. The spectrum was further recorded in between range of 500-4 $000 \mathrm{~cm}-1$. (El-Kassas, et.al; 2016).

\section{REMOVAL METHOD OF ARSENIC FROM WATER}

By using eucalyptus extract, green filter technique was used to obtain metallic nanoparticles. Green synthesis of iron oxide nano materials and their encapsulation into chitosan beads is a new organic/inorganic magnetic hybrid material. Firstly, tap water was used to wash leaves so as to eradicate impurities and dried in oven at $60^{\circ} \mathrm{C}$ overnight. Then, analytical mill further used to ground the biomaterials were sieved and stored in polyethylene flasks. To prepare the extracts molecules ranging diameter between 0.5 and 1 $\mathrm{mm}$ were selected. Add biomass of $1 \mathrm{~g}$ in $100 \mathrm{~mL}$ of pure water. Reflux was used to carry out extract for 40 minutes. Allowed the extract cool down at room temperature. With a coarse filter paper vacuum filtration was conducted. Repetitive procedure was done but this time with a pore size of $0.45 \mu \mathrm{m}$ Cellulose nitrate 
filter from Sartorius of was used to carry out the process. Four different leaves extracts were obtained: Eucalyptus (Eucalyptus globulus), gorse (Ulexeuropaeus), Pine (Pinus pinaster.), Chestnut tree (Castanea sativa). Green synthesis of $\mathrm{Fe} 2 \mathrm{O} 3$ nanomaterials: In eucalyptus extract0.1 $M$ iron metal salt (Fe (NO3) 3 $.9 \mathrm{H} 2 \mathrm{O}$ ) solution was added drop wise. Due to nanoparticles reaction in solution colour changes from dark yellow to black. The whole process was taken out at $25{ }^{\circ} \mathrm{C}$. Various mixtures were made as mentioned proportions: 10:50, 25:50, 50:50, 50:25, 50:10, and 50:5. Based on magnetic hybrid materials synthesis of chitosan: Preparation of iron oxide nanoparticle beads (INPB) was made by the subsequent methods: $30 \mathrm{~mL}$ of a $2 \%$ acetic acid solution was used to dissolve $1.2 \mathrm{~g}$ of chitosan. The chitosan solution was further mixed with $100 \mathrm{~mL}$ of iron oxide nanoparticle suspension. $2 \mathrm{M}$ $\mathrm{NaOH}$ solution is required to dripped the mixture, maintaining agitation during $12 \mathrm{~h} .7$ Chitosan beads were washed with ultrapure water till neutralization occurs and polyethylene bottles were used to store water .Preferred extracts characterization was done by using following procedures: Total antioxidant activity can be determine by DPPH radical scavenging capacity and FolinCiocalteu method which ascertain the total phenolic content of the extracts. FolinCiocalteu process outcome was expressed in miliequivalents of gallic acid per gram of biomass, while outcome from DPPH process expressed in miliequivalents of Trolox per gram of biomass. Transmission Electron Microscopy (TEM) was used for Iron oxide NPs characterization. The morphology of the synthesized NPs can be analysed by this technique. Measurements were done by using a transmission electron microscope, powder diffraction, X-Ray Diffraction (XRD), was used to estimate the arrangement of the iron oxide nanoparticles beads (INPB) .(Martínez-Cabanas, et.al;2016)

\section{DISCUSSION}

Green synthesis of metal oxides and metals nanoparticles has becoming a prepossessing zone of research. Various native essences of flora, bacilli, fungus, and floral distillate have been taken for modeling of substance. Floral distillate has capability of balancing and reductant for making controlled substances. Green filter is used because of its cheap, secure and simply accessible property which helps to purify water and helps in water treatment. There are many differences observed in leaf extract taken from different regions which leads to different results in different research laboratory.

\section{CONClusion}

Contaminants from drinking water can be removed by using green filter nanoparticles it is easily available, sustainable and have no side effects. The application of green filters absolute the tariff of enormous quantity of therapeutic and interval of policy of nanoparticles in correction to habitat. Forthcoming investigation and growth of approaching green particles synthesis should be administered in direction of research laboratory performance to large scale in consideration of current affairs, focusing fitness of human beings and environment issues. Formation of Green filter should be practiced to cure environment and in fields like medicine, meal, beautifying manufacturing.

\section{REFERENCES}

[1] Sadon, F. N., Ibrahem, A. S., \& Ismail, K. N. (2012). An overview of rice husk applications and modification techniques in wastewater treatment. Journal of Purity, Utility Reaction and Environment, 1(6), 338-364.

[2] Opeolu, B.O., Fatoki, O.S., 2012. Dynamics of zinc saption from aqueous matrices using plantain (Musa sp.) peelbiomass, Afr. J. Biotechnol. 11, 13194-13201

[3] Salam H.A., Rajiv P., Kamaraj M, Jagadeeswaran P., Gunalan S. and Sivaraj R., Plants: Green Route for Nanoparticle Synthesis. I. Res. J. Biological Sci., 1, 85-90 (2012)

[4] Bragança LFFPG, Avillez RR, Moreira CR, Paisda Silva MI. Synthesis and characterization of $\mathrm{Co}-\mathrm{Fe}$ nanoparticles supported on mesoporous silicas. Materials Chemistry and Physics. 2013; 138(1):17-28. [ Links ]

[5] Wouters B, Sheng X, Boschin A, Breugelmans $\mathrm{T}$, Ahlberg E, Vankelecom IF, et al. The electrocatalytic behaviour of $\mathrm{Pt}$ and $\mathrm{Cu}$ nanoparticles supported on carbon nanotubes for the nitrobenzene reduction in ethanol. Electrochimica Acta. 2013; 111:405-410 [ Links]

[6] Liu X, Wang A, Li L, Zhang T, Mou CY, Lee $\mathrm{JF}$. Synthesis of $\mathrm{Au}-\mathrm{Ag}$ alloy nanoparticles supported on silica gel via galvanic replacement reaction. Progress in Natural Science: Materials International. 2013; 23(3):317-325. [ Links ]

[7] Li L, Chen M, Huang G, Yang N, Zhang L, Wang $\mathrm{H}$, et al. A green method to prepare Pd$\mathrm{Ag}$ nanoparticles supported on reduced graphene oxide and their electrochemical catalysis of methanol and ethanol oxidation. Journal of Power Sources. 2014; 263:13-21. 
[8] Yamaguchi NU, Bergamasco R, Hamoudi S. Magnetic MnFe2O4-graphene hybrid composite for efficient removal of glyphosate from water. Chemical Engineering Journal. 2016;295:391-402

[9] Kalijadis AM Vukcevic MM, Jovanovic ZM, Lauševic ZV, Lauševic MD. Characterization of surface oxygen groups on different carbon materials by the Boehm method and temperature programmed desorption. Journal of the Serbian Chemical Society. 2011; 76(5):757768.

[10] Hosseini S, Bayesti I, Marahel E, Babadi FE, Abdullah LC, Choong TS. Adsorption of carbon dioxide using activated carbon impregnated with $\mathrm{Cu}$ promoted by zinc. Journal of the Taiwan Institute of Chemical Engineers. 2015; 52:109-117.

[11] P. Trivedi, L. Axe, Environmental Science and Technology 34 (2000) 2215-2223.

Citation: Nikita Verma, Rajeev Kumar, Mahipal SinghSankhla, Kapil Parihar. Green Filter Development: An Innovative Technique for Removal of Heavy Metals from Water. ARC Journal of Forensic Science. 2020 5(1): 7-12.http://dx.doi.org/10.20431/2456-0049.0501002

Copyright: (C) 2020 Authors. This is an open-access article distributed under the terms of the Creative Commons Attribution License, which permits unrestricted use, distribution, and reproduction in any medium, provided the original author and source are credited. 